\title{
Role of Diffusion Tensor Imaging (DTI) in Post Traumatic Spinal Cord Injury
}

\author{
RANIA Z. HASSEN, M.D. and SHAIMA F. EL-KHOLY, M.D. \\ The Department of Radiology, Faculty of Medicine, Cairo University
}

\begin{abstract}
Background: Traumatic injuries of the spine are potentially catastrophic. If associated with neurologic damage, they lead to overwhelming medical, social, and financial consequences. DTI is an advanced neuroimaging technique that is considered sensitive to cord changes not seen on conventional MR imaging.
\end{abstract}

Aim of Study: The aim of this study is to investigate the changes in spinal cord (DTI) parameters in patients with posttraumatic spinal cord injury.

Material and Methods: The study was performed in Radiodiagnosis Department. Kasr El-Aini Hospitals in the period of January 2017 to January 2018. 25 patients presented with spinal cord transection after trauma (group 1) and 15 age matched controls (group 2) were included in this study. Conventional MRI and Diffusion tensor imaging (DTI) were performed in both groups. Time of imaging of group 1 varied between 2 to 4 years after trauma. Fraction anisotropy (FA) value was calculated at multiple levels proximal to the level of injury.

Results: This study demonstrates that FA values for patients with spinal cord injury are significantly lower than values in healthy individuals. Regional measurements of FA values at 5 cord levels showed significant decrease at the level of cord injury.

Conclusion: DTI can be considered sensitive marker of cord injury if compared with conventional MR imaging. It can predict the need for early therapeutic intervention and can be considered as baseline pre-operative study and in follow up post stem cell therapy.

Key Words: MRI - Diffusion tensor imaging - Spinal cord injury - Fractional anisotropy.

\section{Introduction}

POST-TRAUMATIC spinal cord injuries may cause damage to the myelinated fibers of spinal cord and nerve roots, with consequent myelopathy

Correspondence to: Dr. Rania Z. Hassen, The Department of Radiology, Faculty of Medicine, Cairo University
[1]. This spinal cord insult may cause Wallerian degeneration above or below the level of injury. MRI can detect these changes as increased signal intensity on T2 weighted images [2].

Diffusion tensor imaging (DTI) helps in the detection of structural abnormalities in white matter tracts after spinal cord injuries. It can also determine the Wallerian degeneration level as a baseline study for follow-up of these cases post stem cell therapy [3].

DTI is a technique based on the diffusion imaging which depends on the water molecules Brownian motion in biological tissues. The white matter is anatomically located in different directions, with non-uniform diffusion but anisotropic, along the various fiber tracts. Therefore, the measurement of diffusion is not represented as single quantity but is expressed as estimation of a diffusion tensor (D), representing the measurement of water diffusion in different directions [4]

DTI is widely used in the brain for various applications. It was extensively studied in the axonal injury $[\mathbf{5 , 6 ]}$. In case of the diffuse axonal injury, CT scan and conventional MRI may be normal, and there was reduction in diffusion anisotropy after 24 hours, suggestive of axonal injury [5]. Also, it has been documented that signal changes in the conventional MRI may not correlate with neurological findings while DTI correlates with the motor deficits [7].

DTI can help in demonstration of the pattern of affection of the tracts of the white matter by traumatic cord injury so helps in treatment plan especially stem cell therapy and follow-up of cases [8]. 


\section{Patients and Methods}

The study was performed in Radiodiagnosis Department. Kasr El-Aini Hospitals in the period of January 2017 to January 2018.

This study was performed after taking ethics committee approval. Group one consisted of twenty five patients (15 males and 10 females) with spinal cord transection following road traffic accidents. The age range between 33 years to 59 years, with a mean age of 45 years. Time of imaging varied from 2 to 4 years. Group two consisted of 15 age matched normal healthy subjects as a control.

\section{MR imaging:}

Technique was performed using a standard 1.5 Tesla unit (Achieva, Philips). Spine coil was used. The sequences obtained were sagittal and axial T1 and T2 for the whole spine. Diffusion Tensor imaging consisted of single shot spin echo echoplanar in 25 directions. TR (Repetition time): 8500; TE (time to echo): 97.6 ; $b$-value: 1000. Frequency: 128, phase: 128, NEX (number of excitations): 1; FOV (field of view): $26 \times 20.8$; slice thickness: $5 \mathrm{~mm}$ with zero interslice gap; and bandwidth: $250 \mathrm{kHz}$.

All the images were transferred to the workstation (Phillips Extended MR Workspace, 2.6.3.5 Netherlands) for post processing. 3D fiber tractography was done.

For FA measurement, free hand drawing of ROI was done in the axial colour map images. Two voxels at least around the edge of the cord were excluded, so no partial volume contamination from the surrounding CSF. Measurement was done at five levels above the injury level (FA 1 to FA 5). We didn't measure FA value caudal to the cord injury level as many of the lesions were at the conus level.

The FA of control group was measured at the region of the dorsal spinal cord. Several statistical associations between the FA measurements at both patients groups were done as discussed later.

\section{Statistical analysis:}

Paired Student's $t$-test was used for comparison between the mean FA values in the different study groups. $p$-value of $<0.05$ was considered statistically significant. Data were analyzed using SPSS program v23.

\section{Results}

Complete loss of anisotropy was found at the cord transection level. No signal changes were found in the cord at conventional T2 weighted images above and below the lesions levels. FA values were calculated in five ROIs above the cord injury level. Detailed information of the patients, controls and their FA values are listed in Tables $(1,2)$.

By Comparing the mean FA values above the level of injury using the DTI technique, A statistical significant difference was found between FA1 (0.385) and FA2 (0.461) with $p$-equals 0.0007 . No statistical significant difference was found between FA2 (0.461) and FA3 (0.482) with $p$-equals 0.23 . Statistical significant difference was found between FA3 (0.482) and FA4 (0.530) with $p$-equals 0.0023 and between FA4 (0.530) and FA5 (0.591) with $p$ equals 0.0001 .

Comparing FA values between both groups showed a significant statistical difference between FA4 and the mean Fractional anisotropy of the control $(p-0.0011)$ while no statistical difference was found between FA5 and the FA mean of the controls $(p-0.7411)$. Figs. $(1,2)$.

Table (1): Detailed information of the control group.

\begin{tabular}{lllll}
\hline $\begin{array}{l}\text { Patient } \\
\text { No. }\end{array}$ & Age & sex & $\begin{array}{c}\text { Level of } \\
\text { measurement }\end{array}$ & FA \\
\hline 1 & 54 & M & D11 & $0.691 \pm 0.175$ \\
2 & 50 & F & D9 & $0.557 \pm 0.164$ \\
3 & 32 & M & D8 & $0.587 \pm 0.130$ \\
4 & 45 & M & D3 & $0.634 \pm 0.221$ \\
5 & 57 & M & D10 & $0.755 \pm 0.224$ \\
6 & 43 & M & D6 & $0.573 \pm 0.244$ \\
7 & 50 & F & D5 & $0.506 \pm 0.192$ \\
8 & 34 & F & D10 & $0.566 \pm 0.239$ \\
9 & 52 & F & D9 & $0.573 \pm 0.173$ \\
10 & 46 & F & D2 & $0.573 \pm 0.244$ \\
11 & 55 & M & D3 & $0.576 \pm 0.153$ \\
12 & 42 & F & D12 & $0.547 \pm 0.277$ \\
13 & 49 & F & D11 & $0.567 \pm 0.212$ \\
14 & 43 & M & D9 & $0.654 \pm 0.162$ \\
15 & 54 & F & D7 & $0.595 \pm 0.262$ \\
Mean & & & & 0.59693 \\
SD & & & & 0.06264 \\
\hline
\end{tabular}


Table (2): Detailed information of the patients group.

\begin{tabular}{|c|c|c|c|c|c|c|c|c|}
\hline $\begin{array}{l}\text { Patient } \\
\text { No. }\end{array}$ & Age & Sex & $\begin{array}{l}\text { Level of } \\
\text { injury }\end{array}$ & FA 1 & FA 2 & FA 3 & FA 4 & FA 5 \\
\hline 1 & 40 & M & D11 & $0.341 \pm 0.169$ & $0.449 \pm 0.247$ & $0.495 \pm 0.123$ & $0.521 \pm 0.169$ & $0.617 \pm 0.189$ \\
\hline 2 & 50 & $\mathrm{~F}$ & D9 & $0.297 \pm 0.146$ & $0.379 \pm 0.277$ & $0.418 \pm .0143$ & $0.531 \pm 0.189$ & $0.641 \pm 0.199$ \\
\hline 3 & 55 & M & D8 & $0.398 \pm 0.173$ & $0.493 \pm 0.258$ & $0.521 \pm 0.128$ & $0.571 \pm 0.192$ & $0.612 \pm 0.195$ \\
\hline 4 & 52 & M & D3 & $0.389 \pm 0.173$ & $0.533 \pm 0.258$ & $0.541 \pm 0.128$ & $0.521 \pm 0.165$ & $0.647 \pm 0.185$ \\
\hline 5 & 41 & M & D10 & $0.315 \pm 0.177$ & $0.384 \pm 0.258$ & $0.444 \pm 0.268$ & $0.515 \pm 0.348$ & $0.604 \pm 0.182$ \\
\hline 6 & 57 & M & D6 & $0.379 \pm 0.171$ & $0.510 \pm 0.137$ & $0.447 \pm 0.307$ & $0.491 \pm 0.270$ & $0.545 \pm 0.225$ \\
\hline 7 & 45 & $\mathrm{~F}$ & D5 & $0.208 \pm 0.070$ & $0.345 \pm 0.189$ & $0.348 \pm 0.184$ & $0.467 \pm 0.216$ & $0.595 \pm 0.217$ \\
\hline 8 & 47 & $\mathrm{~F}$ & D10 & $0.345 \pm 0.149$ & $0.382 \pm 0.245$ & $0.437 \pm 0.307$ & $0.481 \pm 0.277$ & $0.585 \pm 0.225$ \\
\hline 9 & 52 & $\mathrm{~F}$ & D9 & $0.336 \pm 0.149$ & $0.410 \pm 0.091$ & $0.457 \pm 0.303$ & $0.421 \pm 0.237$ & $0.575 \pm 0.215$ \\
\hline 10 & 45 & $\mathrm{~F}$ & D2 & $0.484 \pm 0.147$ & $0.594 \pm 0.147$ & $0.535 \pm 0.240$ & $0.571 \pm 0.270$ & $0.624 \pm 0.207$ \\
\hline 11 & 48 & $\mathrm{M}$ & D3 & $0.490 \pm 0.186$ & $0.553 \pm 0.143$ & $0.520 \pm 0.231$ & $0.584 \pm 0.223$ & $0.596 \pm 0.251$ \\
\hline 12 & 50 & $\mathrm{~F}$ & D12 & $0.497 \pm 0.077$ & $0.540 \pm 0.007$ & $0.495 \pm .0122$ & $0.541 \pm .0162$ & $0.657 \pm 0.129$ \\
\hline 13 & 52 & $\mathrm{~F}$ & D11 & $0.424 \pm 0.094$ & $0.525 \pm 0.951$ & $0.534 \pm 0.212$ & $0.579 \pm 0.260$ & $0.536 \pm 0.267$ \\
\hline 14 & 45 & M & D9 & $0.424 \pm 0.094$ & 0.495 & 0.418 & $0.537 \pm .0159$ & $0.664 \pm .0 .219$ \\
\hline 15 & 56 & $\mathrm{~F}$ & D7 & $0.202 \pm 0.079$ & $0.328 \pm 0.141$ & 0.420 & 0.557 & $0.541 \pm 0.241$ \\
\hline 16 & 43 & M & D3 & 0.418 & $0.477 \pm$ & $0.512 \pm 0.277$ & 0.547 & $0.556 \pm 0.221$ \\
\hline 17 & 54 & M & D6 & $0.381 \pm 0.173$ & $0.415 \pm 0.250$ & $0.520 \pm 0.232$ & $0.547 \pm 0.225$ & $0.556 \pm 0.235$ \\
\hline 18 & 59 & $\mathrm{~F}$ & D2-6 & $0.360 \pm 0.162$ & $0.448 \pm 0.192$ & 0.529 & $0.567 \pm 0.206$ & $0.554 \pm 0.231$ \\
\hline 19 & 38 & M & D2 & $0.383 \pm 0.158$ & $0.470 \pm 0.163$ & $0.532 \pm 0.124$ & $0.569 \pm 0.265$ & $0.574 \pm 0.214$ \\
\hline 20 & 52 & $\mathrm{M}$ & D12 & $0.474 \pm 0.124$ & $0.533 \pm 0.159$ & $0.510 \pm 0.254$ & $0.587 \pm 0.225$ & $0.641 \pm 0.251$ \\
\hline 21 & 35 & $\mathrm{M}$ & D11 & $0.486 \pm 0.188$ & $0.511 \pm 0.172$ & $0.528 \pm 0.254$ & $0.574 \pm 0.252$ & $0.596 \pm 0.256$ \\
\hline 22 & 55 & M & D7 & $0.387 \pm 0.118$ & $0.441 \pm 0.157$ & $0.510 \pm 0.231$ & $0.582 \pm 0.223$ & $0.615 \pm 0.124$ \\
\hline 23 & 42 & $\mathrm{~F}$ & D6 & $0.403 \pm 0.125$ & $0.433 \pm 0.179$ & $0.534 \pm 0.260$ & $0.578 \pm 0.270$ & $0.614 \pm 0.207$ \\
\hline 24 & 33 & M & D3 & $0.383 \pm 0.158$ & $0.371 \pm 0.163$ & $0.410 \pm 0.224$ & $0.401 \pm 0.221$ & $0.515 \pm 0.178$ \\
\hline 25 & 45 & M & D10 & $0.426 \pm 0.139$ & $0.499 \pm 0.174$ & $0.440 \pm 0.126$ & $0.433 \pm 0.189$ & $0.525 \pm 0.270$ \\
\hline Mean & & & & 0.385 & 0.461 & 0.482 & 0.530 & 0.591 \\
\hline SD & & & & 0.07689 & 0.07073 & 0.05323 & 0.05379 & 0.04259 \\
\hline
\end{tabular}

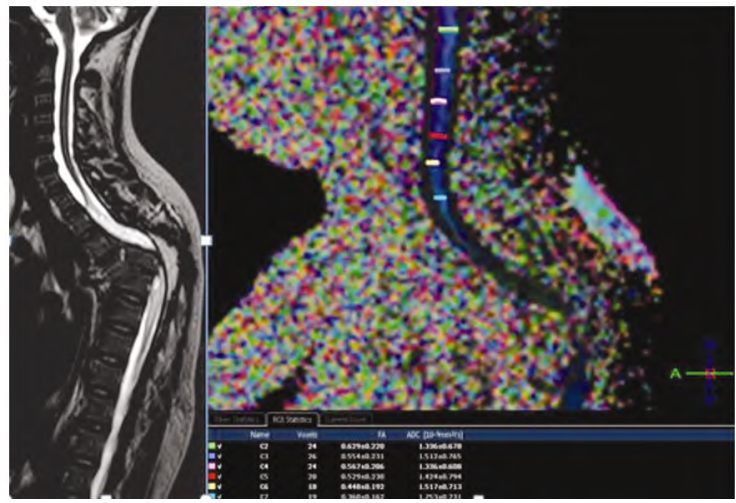

Fig. (1): (A-B) 59 year old male presented 2 year after complete cord transection following motor car accident. (A) sagittal T2WI images shows fracture dislocation at D5-6 level with complete cord transection from D2 to D6. No signal abnormality detected within the cord proximal to the injury level. Cord thinning was noted at D1 level (B) sagittal color coded FA map showing marked reduction of the Fractional anisotropy value at D1 $0.360 \pm 0.162$ with gradual improvement cranially reaching $0.554 \pm 0.231$ at $\mathrm{C} 4$ level. Complete loss of anisotropy was found at the cord transection level.

\section{Discussion}

Post-traumatic injury of the spinal cord may result in Wallerian degeneration above or below the level of injury which may be detected by Conventional MRI as increased T2 signal and cord thinning [2]. DTI can detect the structural abnormalities and Wallerian degeneration of the tracts

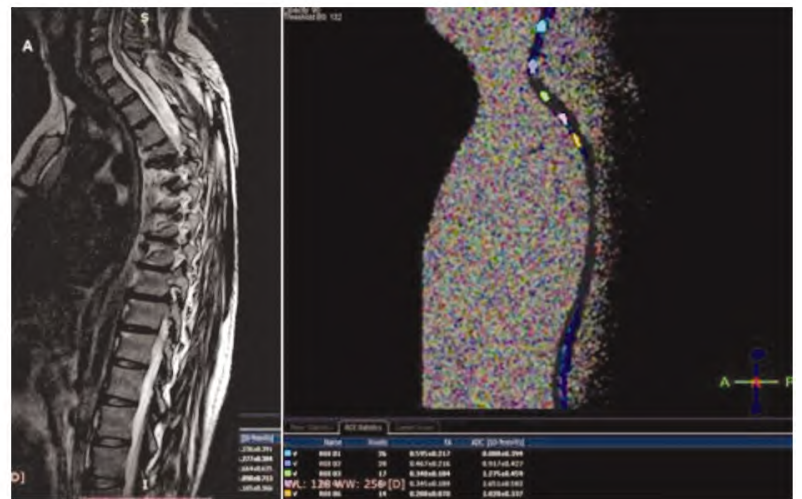

Fig. (2): (A-B). 45 year old female presented 3 year after complete cord transection at D5 level following motor car accident. No abnormal signal detected within the cord proximal to the level of injury. Thinning of the cord was noted at D4 level (B) sagittal color coded FA map showing marked reduction of the FA value at D4 $0.208 \pm 0.070$ with gradual improvement cranially reaching $0.595 \pm 0.217$ at C7 level. Complete loss of anisotropy was found at the level of cord transection.

of the white matter following cord injury and also can be considered as a baseline study for followup of these cases post stem cell therapy [3].

We studied the changes of DTI in the spinal cord transection patients. We found significantly decreased FA values in the cord just above the injury site in relation to FA values more cranially. 
Normalization occurred at the level of the 5 th proximal vertebra. In all cases, we didn't find any T2 signal abnormalities within the cord above or below the injury level. Our findings suggest the associated ascending and descending Wallerian degeneration, which can be detected by DTI even in normally appearing cord at conventional MR imaging [9].

All our cases presented with complete cord transection so FA value was reduced to 0 (complete loss of anisotropy) due to total disruption of the tracts of white matter.

A study done by [10]; they showed the role DTI in detection of Wallerian degeneration after injury of the spinal cord. Their study was done in the spinal cord of 29 patients and the FA was calculated for patients and controls followed by comparison of the values. They showed that the mean FA value was $0.550 \pm 0.09$ in their control group and $0.367 \pm$ 0.14 in the patients with statistically significant difference $(p=0.001)$ [10].

In the study done by [11], FA was significantly lower at the chronic lesion and appeared dependent on the completeness of the injury. FA of subjects with complete injury were significantly lower when compared with those with incomplete injury $(p<.001)$; however, the level of injury was not a significant. Progressive demyelination was documented in the chronic stages of injury remote from the lesion with subsequent remyelination that lead to axons with decreased thickness of the myelin sheath. These microstructure changes could be the cause of the changes in diffusivity in the spinal cord [11]

Wallerian degeneration above or below the injury level was detected by pathological examinations $[2,12]$, showed that there is sequential loss of the myelin proteins during Wallerian degeneration after cord injury that can be seen many years after injury. Similarly, tensor imaging in the cord of a rat model with cord contusion showed changes in the ADC with recovery in values of ADC with time a feature suggestive that recovery from spinal cord injury is a dynamic process that may remain for years [13].

In another study done by [14], they measured the FA value at the cord injury level in 20 cases of acute cervical trauma and 30 ages and sex matched healthy controls. They found the Mean FA value at the injury level is $(0.43 \pm 0.08)$ less than in controls $(0.62 \pm 0.06)$, which was considered statistically significant ( $p$-value $<0.001$ ). The reduced FA values were explained by the restricted water molecules anisotropic diffusion in the injured cord. The FA measures the myelination degrees with higher FA values are suggestive of more intact spinal nerves. [14].

Recently, stem cell therapy for patients with spinal cord injury is being tried with the hope of achieving axonal regeneration and recovery $[15,16]$ The use of stem cells in patients with spinal cord injury is a promising therapy. Thus, tensor imaging can be noninvasively identifying axonal regeneration after stem cell therapy.

In conclusion, DTI technique is considered beneficial base-line study for evaluation of post traumatic cord injury and in follow-up after therapy. It can detect Wallerian degeneration, which is not detected on routine imaging Wallerian degeneration of the cord occurs proximal to the cord transection level and improves at more cranial levels. It extends up to the 4 th vertebral level with normalization of the FA value could be detected at the fifth vertebral level. This can help to improve the MRI technique by decreasing the scan coverage and time of examination thus improving the image quality.

\section{References}

1- LIN V., CARDENAS D., CUTTER N.C , et al.: Spinal Cord Medicine: Principles and Practice ${ }^{2 \text { nd }}$ ed. New York: Demos Medical Publishing, 2002.

2- BECERRA J.L., PUCKETT W.R., HIESTER E.D., et al.: MR-pathologic comparisons of Wallerian degeneration in spinal cord injury. AJNR. Am. J. Neuroradiol., 16: 125133, 1995.

3- HESSELTINE S.M., LAW M., BABBA J., et al.: Diffusion tensor imaging in multiple sclerosis: Assessment of regional differences in the axial plane within normalappearing cervical spinal cord. AJNR. Am. J. Neuroradiol. 27: 1189-1193, 2006.

4- GUPTA S., PATEL Z. and MISRA B.: Pictorial essay: Neurosurgical application and physics of diffusion tensor imaging with 3D fiber tractography. Indian. J. Radiol. Imaging., 18: 37-44, 2008.

5- ARFANAKIS K., HAUGHTON V.M., CAREW J.D., et al.: Diffusion tensor MR imaging in diffuse axonal injury. AJNR. Am. J. Neuroradiol., 23: 794-802, 2002.

6- INGLESE M., MAKANI S., JOHNSON G., et al.: Diffuse axonal injury in mild traumatic brain injury: A diffusion tensor imaging study. J. Neurosurg., 103: 298-303, 2005.

7- CHANG Y., JUNG T.D., YOO D.S., et al.: Diffusion tensor imaging and fiber tractography of patients with cervical spinal cord injury. J. Neurotrauma., 27: 2033-2040, 2010.

8- VARGAS M.I., DELAVELLE J., JLASSI H., et al.: Clinical applications of diffusion tensor tractography of the spinal cord. Neuroradiology, 50: 25-29, 2008. 
9- MOHAMED F.B., HUNTER L.N., BARAKAT N., et al.: Diffusion tensor imaging of the pediatric spinal cord at 1.5T: Preliminary results. AJNR. Am. J. Neuroradiol., 32: 339-345, 2011.

10- KAMBLE B., VENKATARAMANA K., NAIK L., et al.: Diffusion tensor imaging in spinal cord injury. Indian Journal of Radiology and Imaging, 21: 221-224, 2011.

11- ELLINGSON B.M, ULMER J.L., KURPAD S.N., et al.: Diffusion Tensor MR Imaging in Chronic Spinal Cord Injury. American Journal of Neuroradiology, 29: 19761982, 2008.

12- BUSS A., PECH K., MERKLER D., et al.: Sequential loss of myelin proteins during Wallerian degeneration in the human spinal cord. Brain, 128: 356-364, 2005.

13- ELLINGSON B.M., KURPAD S.N. and SCHMIT B.D.
Ex vivo diffusion tensor imaging and quantitative tractography of the rat spinal cord during long-term recovery from moderate spinal contusion. J. Magn. Reson. Imaging, 28: 1068-1079, 2008.

14- D'SOUZA M., CHOUDHARYB A., POONIA M., et al.: Diffusion tensor MR imaging in spinal cord injury. Injury, Int. J. Care. Injured., 48: 880-884, 2017.

15- MATHAI K.I., SASIVADANAN., SUDUMBRAKER S., et al.: Stem cell therapy for spinal cord injury A plea for rationality. Indian. J. Neurotrauma., 5: 7-10, 2008.

16- PAL R., VENKATARAMANA N.K., JAN M., et al.: Ex vivo-expanded autologous bone marrow-derived mesenchymal stromal cells in human spinal cord injury/paraplegia: A pilot clinical study. Cytotherapy, 11: 897-911, 2009.

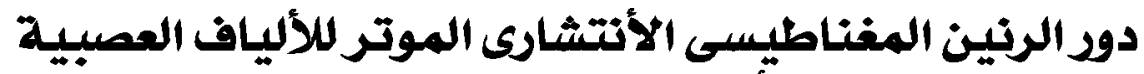

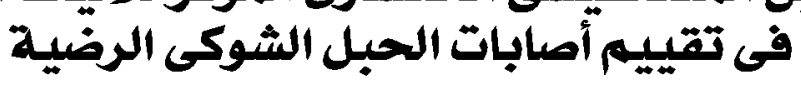

$$
\begin{aligned}
& \text { الأصابات الرضية للعمود الفقرى قد تكن كارثية. إذا أرتبطت بضرد عصبى، يمكن أن تؤدى إلى عواقب طبية } \\
& \text { وأجتماعية ومالية هائلة. }
\end{aligned}
$$

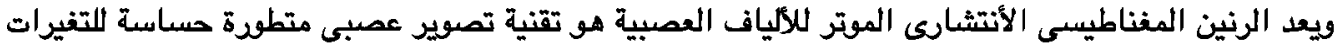

$$
\begin{aligned}
& \text { الدقيقة فى النخاع الشوكى التى لا تظهر فى التصوير بالرين للافين المغناطيسى التقليدى. }
\end{aligned}
$$

